\title{
How to Enhance Focused Attention of Organization Members on Their Learning Process
}

\author{
Fen Sun, Yinqiu Ma* \\ School of Business, Nanjing University of Information Science and Technology, Nanjing, China \\ Email: sunfen_nuist@sina.com, ^watianqiuzi@126.com
}

How to cite this paper: Sun, F., \& Ma, Y. Q. (2020). How to Enhance Focused Attention of Organization Members on Their Learning Process. American Journal of Industrial and Business Management, 10, 1155-1161.

https://doi.org/10.4236/ajibm.2020.106078

Received: April 21, 2020

Accepted: June 26, 2020

Published: June 29, 2020

Copyright ( 2020 by author(s) and Scientific Research Publishing Inc. This work is licensed under the Creative Commons Attribution International License (CC BY 4.0).

http://creativecommons.org/licenses/by/4.0/

\begin{abstract}
In the process of learning, the duration of focused attention may vary from sustained concentration to short-lived attention or just momentary notice. This article is meant to describe the psychological behaviors displayed by organization members in their learning process: no response to the object of learning, attention focused on learning and sustained attention through various activities. The analysis of causes of "distraction" herein is followed by a presentation of strategies devoted to focused attention. Heuristic teaching methods and creation of appropriate conditions may give rise to concentration of attention.
\end{abstract}

\section{Keywords}

Organization Members, Teacher, Learner, Concentration, Learning Process

\section{Introduction}

The difference between a good student and an ordinary one lies in the control of focused attention (Ke, 2018). The duration of attention varies according to the length of time in which organization members are engrossed during the learning process. Sustained attention can be kept throughout the process of learning in which the learner is absorbed for a certain task, mission or problem. This type of concentration may also be momentary, that is, it may be on and off and on again in a brief period of time. In a 2015 paper, researcher Sun Lingli came to the conclusion: "A good memory is an important guarantee for successful studies, and focused attention is the prerequisite for a great realistic significance for their deep-going studies. The sustained concentration of attention will enable the *Corresponding author. 
learners to throw themselves heart and soul into the learning process, and constantly raise their learning and work efficiency. Meanwhile, maintaining a high level of focused attention is the fundamental condition for perception, memorization and thinking in the human brain." (Sun, 2015) Without fixed attention, one can never be involved in certain skillful and somewhat risky sports such as boxing, arrow-shooting, raps shooting, high-platform diving, alpine skiing and acrobatic gymnastics. Students unable to concentrate their attention cannot do well in many scholastic subjects, abstract or practical. People devoid of focused attention will be likely to end up in failure in their professional careers.

However long the duration of concentrated attention may be, both instructor and learner desire to have their attention riveted onto the learning process. On the contrary, none of the organization members want to see the "distraction" of attention in the learning process.

\section{The Organization Members' Attention Focused on the Learning Process: Psychoanalysis and Characteristics of the Learning Process (Psychoanalysis and Characteristic)}

What characteristic features are displayed in the process of an individual's engrossment in a learning task?

\subsection{No Response to Matters Not Related to the Learning Process}

Perception and awareness are human reflection of objective realities both being part of perceptional knowledge. Perception is the combination of various types of information received by the sense organs, while awareness is the overall reflection of a matter. Perception is the simple processing of information by the brain. And awareness is the result of the integrated processing of information by the various functional areas of the brain. Awareness provides meaning for the object perceived by the individual. Generally speaking, we divide awareness into physical awareness and social awareness. The process of awareness includes attention, organization, explanation, index-searching and judgement (Sun, 2019).

In the monograph Heart of Yoga, T.K.V. Desikachar proposed the concept of "sensation prevention", which means terminating the nourishment of sense organs and driving away all the function of sense organs. What does it all mean? It means that our sense organs do not always rely on or receive any stimulants and thereby are not always nourished by the stimulants. He alleges that if we are so deeply absorbed in something, even the most enchanting setting-sun is not in a position to arrest our attention. If we are in a state of shut-down of all senses, we will be ignorant of anything that may give off all its charms because our sense organs will remain indifferent and unaffected (Desikachar, 2014).

Children may divert their attention because of petty actions, looking away at irrelevant things or touching meaningless objects. Even adults may not be able to concentrate their attention and become absent-minded, reading text messages on the phone or chatting with pals and saying things irrelevant to their learning. If we say that absent-mindedness results from disruptive noises, meaningless 
objects, odors and so on. Then concentrated attention will bring about prevention of all other sensations; all other factors (irrelevant to his learning) will never attract one's attention. When an individual is deeply absorbed in learning, all his sense organs will exit, never to be attracted or stimulated by anything unrelated to learning. When all sense organs make their exit, the mind is exceedingly sensitive to learning, then the individual will be wholly devoted to the learning process. Having entered into the state of complete shut-down of all senses, the individual will be engrossed in the learning process, ignoring all outside interferences and indifferent to what is going on around him. He will not respond to any other thing than the learning process itself. When asked a question, the individual will respond clearly by trying his best to expound his views.

To sum up, with all attention riveted, the individual will not respond to anything else than learning itself, or his senses will not react even with his sensations perceived.

\subsection{Attention Concentrated on Learning}

Attention that is concentrated represents an ability to direct all one's attention exclusively to something special. Note that this is an agelong eternal topic for discussion. The Russian educationist Ushenski pointed out succinctly, "Attention is the only door to our mind. Whatever is in our consciousness has to come through this door into our mind. Attention is the direction and concentration of our psychological activities when we deal with a matter in the outside world."

According to Desikachar, "focused attention is meant to divert all one's attention in a certain direction. We can create conditions to concentrate our attention on a certain matter without any distraction." (Desikachar, 2014)

\subsection{The Learner Is All along Active, though Learning Activities May Come in Various Forms}

There are various learning styles in which people are engaged in learning. Whatever he is doing, the learner should take an active part, maintaining his motivation, enthusiasm, curiosity and even excitement.

\section{Causes of the Learner's "Distraction"}

After analyzing a questionnaire investigation of 216 second-year college students, researcher Xu Xiurong came up the following conclusion in a 2020 paper: "In relation to the causes of distraction in class, it is revealed that $90 \%$ of the college students feel that their attention level is somewhat affected for various reasons, indicating that deconcentration of attention in class is a very serious problem in college education. $74 \%$ of the college students believe that their attention in class was negatively affected by the instructor's inferior teaching methods. More than $50 \%$ of the college students think that their attention level is negatively influenced by the following factors: watching the internet videos on the mobile phone, failure to prepare for lessons before class, being unable to ${ }^{1}$ https://baike.baidu.com/item/\%E6\%B3\%A8\%E6\%84\%8F\%E5\%8A\%9B/4551258?fr=aladdin. 
keep pace with the instructor's teaching tempo, dislike for the course being taught, lack of sleep causing listlessness, and so on. $25 \%$ of the college students find themselves simply tired of college studies." (Xu et al., 2010)

Distraction, undesirable to both teachers and learners, is shown in such behaviors as slackness, indiscipline, refusal to participate in activities or interactions, indifference, ignorance, two-mindedness, and listlessness. In class, the learner may be seen frequently watching mobile-phone videos, looking at outside scenes, listening to music from the earphone, chatting about meaningless things. The learner may even fall into a doze.

Distraction is caused by the following factors. The content of the text-book is not integrated with realistic needs with its abstractness being unbearable. What the student has to learn is inferior in quality or simply useless. The teacher's methods are unbearably boring. Not devoted to his profession, the teacher uses the force-feeding method which lacks variety and interaction. In face of the teacher who is indifferent, passive and lacking in initiative and enthusiasm, the students may feel ignored or slighted.

\section{Strategies for Fastening the Learner's Attention upon the Learning Process}

Focused attention arises in a natural way. So, simple orders or rules may not successfully force the students into a state of concentrated attention. Effective learning is a type of highly complicated thinking activity. Supervisors may not find out whether the learner is highly attentive or not. However, we can devise some methods to help the learner to get into a state of concentrated attention. From a 2020 study based on a nameless questionnaire, researcher Xu Xiurong concluded: " $57 \%$ of the college students think of the instructor's humour in teaching as something of first importance. The teacher should endeavour to enliven the classroom atmosphere and adopt various flexible teaching styles so as to positively enhance the level of the students' fixed attention." (Xu et al., 2010)

\subsection{Focused Attention May Emerge from the Teacher's Diverting the Learner's Thinking to the Lesson Being Studied}

During the long period of intensive study, the brain works actively and incessantly. This type of thinking does not lead to drifting fantacies, but is steadily targeted to the material being studied which might be a point of knowledge, a section or a problem. Absorption in learning, even pondering long and hard over a problem, will enable one to concentrate his attention. In a state of concentrated attention, people may be engaged in various activities such as dialogs, exchanging different ideas, discussing a topic or composing a novel. Your thinking remains active and stable like a deep river running quietly. So, guiding the learner to think hard will lead to focused attention.

1) Place high-quality teaching at the core

It is hard for the teaching material intended for the ability to use a certain tool 
or for the attainment of a certain goal to really arouse the learner's intensive thinking or focused attention. In college, when the student is forced to study a certain course merely because he knows that what is being taught will be included in the final test which covers all the knowledge expounded in the coursebook. So, the student has to acquire the book knowledge in order to pass the test for the fulfillment of the required number of credits before graduation from college.

The learner may devote some of his attention to his studies when he realizes that the study of the coursebook is related to examinations, promotions, wage-increases and so on, but this type of attention will not last long. As a matter of fact, the leaner may feel pains down at heart, and he may even feel bored or tired. When the learning process is oriented to the required test, the learner draws his attention only to the usefulness of the result, but not to the delight derived from the course of learning. In order to obtain the desired result, the learner has to bear the painful boredom of the learning process.

However, the process-oriented and high-quality teaching is likely to arouse prolonged attention. With his kind of teaching, the learner feels delighted and excited with a high sense of achievement. "The pleasure experienced by the learner while doing something with deliberate attention can be regarded as a burst of deep conscientiousness by which we mean that you can take a challenge conscientiously." (Csikszentmihalyi, 1988) Factors required by a flow of conscientiousness are expertise, clarity and logical coherence which, being somewhat challenging, correspond with the learner's ability to understand and utilize the knowledge imparted by the teacher. The materials taught in class constitute a complete system and fall into various subsystems.

The different pieces of knowledge are intimately interconnected, and none of them can be missing. The learner can easily comprehend what the teacher explains. In a high-quality class of instruction, the teacher represents a good image with fine qualities, fluent language, clear thinking, proper methods, elastic temperament and full vigor and vitality. The teacher can express himself in explicit terms with clear and presice articulation.

2) Excellent teaching methods for the concentration of the students' attention

The teacher should have a good command of the material to be taught, and a clear-cut goal of teaching. With a good mastery of the frame of teaching, the teacher is supposed to know each and every point of the required knowledge and know how to highlight the major and difficult points. The teacher's exposition should be done in a clear, heuristic and enlightening manner so that the students can easily understand what the teacher explains in class.

3) Provide case studies

Case analyses are designed to enhance the students' concentrated attention. The specific cases are acceptable and understandable to the students. In a case study, logicality, clarity, and theory are closely integrated. For the purpose of problem-solving, the students are asked questions which they will ponder upon 
and discuss. To stimulate the students' attention, the teacher selects intriguing cases that are hot issues of the society, enchanting new stories with a complicated plot.

4) Insert heuristic questions

The teacher can design some questions concerning major or difficult points of the textbook, guiding the students in their discussion and bringing-their initiative and creative ability into full play on the condition that the questions are closely linked to the course book.

Armed with relevant questions, the learner will set their brains working actively. Following the students' discussion about the question, the teacher goes on to give a summary with some explanation.

5) Recommend a student to mount the platform to address his classmates, making some comments on the teaching material

The student may desire to be paid attention to. So, standing on the platform to make a speech may have their desire satisfied. The student had better make good preparations long before the presentation. With many eyes focused on him, the student will endeavour to put on a good performance. At the same time, his classmates are requested to comment on his presentation. Therefore, the others also concentrate their attention and rack their brains.

\subsection{Create Appropriate Conditions for Desirable Concentration of Attention}

1) The setting of the learning environment

The lecture room should be made simple, clean, tidy, cozy and pleasant without anything to distract the students' attention.

2) The teacher's appearance and voice

The teacher is supposed to wear clothes with tender colors in a simple style. The teacher's image, dignified or lively, with light make-up and neatly-dressed hair will leave a good impression on the students. The teacher is expected to speak in a natural, calm and tenderly pleasant voice, and vary his tone and pitch according to what is being taught. The teacher's infectious tone will surely appeal to the attentive students.

3) Positive emotions

Emotions that are positive can help one to be happy and achieve successes and help one to be carefree in throwing himself into learning. The teacher needs to steady his emotions and appear to the cheerful and agreeable. Among the positive emotions are anticipation, gladness and acceptance. On the contrary, horror, anger and indifference are negative emotions, most unwelcome among the students.

4) Frequent use of the multimedia

The use of the multimedia serves to arouse the students' attention. The multimedia can provide vivid and interesting pictures and videos. Therefore, insertion of some cartoons, pictures or movies may enliven the classroom atmos- 
phere, only if they are suitable to the learners' age.

\section{Wrap-Up and Inadequacy of the Present Paper}

\subsection{Conclusions of the Paper}

1) The paper is meant to describe the psychological and behavioral characteristics of organization members' focused attention on their learning process.

2) This paper provides the analysis of the causes of the learners' distraction in class.

3) Some high-quality teaching methods are recommended for the purpose of arousing the learners' fixed attention in class.

4) An appropriate learning environment should be established for the emergence of fixed attention.

\subsection{Inadequacy of the Paper}

Owing to the limited knowledge, the present writer of the paper is not in a position to offer more effective strategies for sustaining the organization members' focused attention to their learning process, and therefore is prepared to invite some experts in this field of study to gather more expertise by way of brain-storming for a future induction and summing-up.

\section{Acknowledgements}

This work was supported by the National Social Science Fund of China under grant number 15BGL107.

\section{Conflicts of Interest}

The authors declare no conflicts of interest regarding the publication of this paper.

\section{References}

Csikszentmihalyi, M. (1988). Optimal Experience: Psychological Studies of Flow in Consciousness (pp. 15-35). Cambridge: Cambridge University Press.

Desikachar, T. K. V. (2014). Heart of Yoga. Beijing: Electronics Industry Press.

Ke, B. (2018). Concentrated Attention Is More Important Than Diligence. Journal of Shanghai Education Research, 88.

Sun, J. M. (2019). Organization Behaviors. Beijing: Higher Education Press.

Sun, L. L. (2015). Methods for Enhancing College Students' Fixed Attention. Agriculture of Human Province, 26-27.

$\mathrm{Xu}, \mathrm{X}$. R. et al. (2010). Main Factors Affecting College Undergraduates' Fixed Attention. Journal of Stock Farming Ecology, 94-96. 